\title{
Enucleation following treatment with intravenous pentamidine for Acanthamoeba sclerokeratitis
}

\author{
This article was published in the following Dove Press journal: \\ Clinical Ophthalmology \\ 29 September 2010 \\ Number of times this article has been viewed
}

\section{Rebecca A Kuennen \\ Reynell Harder Smith \\ Thomas F Mauger \\ Elson Craig \\ Department of Ophthalmology, The Ohio State University, \\ Columbus, Ohio, USA}

Correspondence: Thomas F Mauger The Ohio State University, Havener Eye Institute, Department of Ophthalmology, 91 5 Olentangy River Road, Columbus, Ohio 43212 , USA

Tel +l 6142935635

$\mathrm{Fax}+\mathrm{I} 6142933167$

Email thomas.mauger@osumc.edu
Purpose: To describe the course and outcome of treatment of advanced Acanthamoeba sclerokeratitis with intravenous pentamidine.

Methods: A case of advanced Acanthamoeba sclerokeratitis was resistant to conventional therapy and was treated with intravenous pentamidine. The eye was later removed due to incapacitating pain.

Results: The eye showed Acanthamoeba organisms within the cornea and evidence of acute and chronic inflammation throughout the remainder of the eye. The patient has survived without orbital recurrence for 2 years.

Conclusions: This case demonstrates late inflammation with active Acanthameoba keratitis following systemic pentamidine therapy.

Keywords: keratitis, scleritis

\section{Introduction}

Acanthamoebal sclerokeratitis is an uncommon and severe complication of advanced Acanthamoeba keratitis (AK). ${ }^{1-3}$ Despite intensive medical and surgical treatment, enucleation may be required to manage this disease. Pentamidine has shown effectiveness against Acanthamoeba with synergistic effects when used in combination with polyhexamethylene biguanide (PHMB). ${ }^{4-10}$ In vitro testing may not always be associated with in vivo effectiveness. ${ }^{11}$

\section{Case report}

A 59-year-old female presented for a second opinion with previously diagnosed AK of her right eye. She was a daily soft contact lens wearer for many years. The contact lens type and solution were unknown, but she did wash her contact lens case out with tap water on a regular basis. She first noted pain and decreased vision in the right eye approximately 2 years earlier and saw an ophthalmologist. A ring stromal opacity was seen and she was treated for herpetic keratitis. Several months later she was diagnosed with acute retinal necrosis and was hospitalized and treated with foscarnet. The patient underwent penetrating keratoplasty in the right eye 9 months after initial treatment for presumed corneal opacity secondary to herpes simplex keratitis. The pathological examination of the corneal button demonstrated Acanthamoeba cysts. The eye was treated with topical antiamoebal therapy and systemic fluconazole. Treatment was continued for 1 year when the patient presented at our institution for a second opinion. 
Her ocular medications on presentation were: topical PHMB every 2-3 hours, topical propamidine (Brolene ${ }^{\circledR}$ ) three times per day, topical moxifloxacin $\left(\right.$ Vigamox $\left.^{\circledR}\right)$ three times per day, prednisolone actetate $1 \%$ every $2-3$ hours, and dorzolamide-timolol $\left(\operatorname{Cosopt}^{\circledR}\right)$ three times per day. She was also on oral famcyclovir and fluconazole. She had apparently had multiple (10-12) subtenons injections of triancinolone $\left(\right.$ Kenalog $\left.^{\circledR}\right)$ over the past year.

On examination, visual acuity in the right eye was hand motion at 1 foot with light projection in all quadrants. Visual acuity in the left eye was 20/20 with correction. The cornea showed a penetrating graft with moderate stromal edema and epithelial bedewing. Grade one fine keratic precipitates were also present (Figures 1A and 1B). The sclera showed

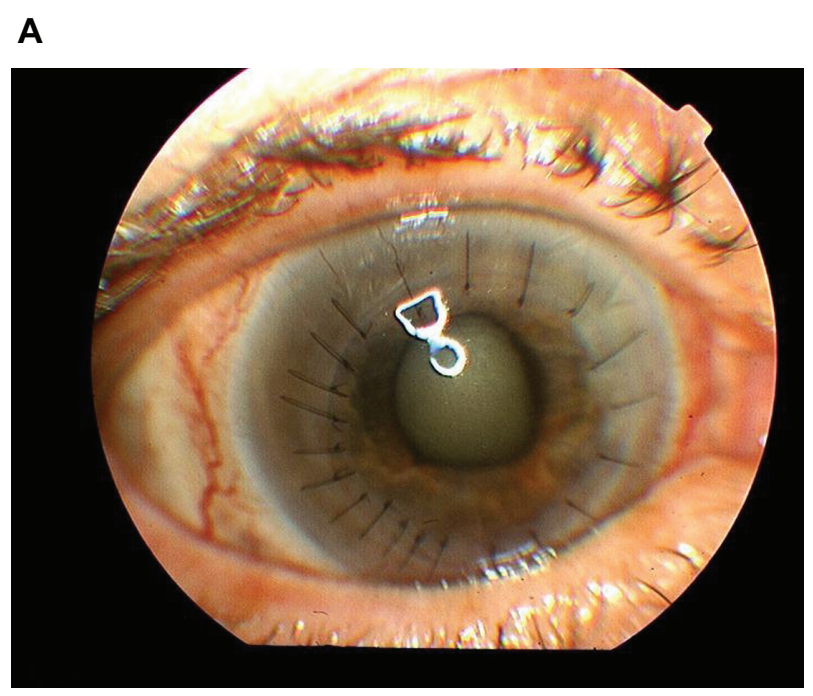

\section{B}

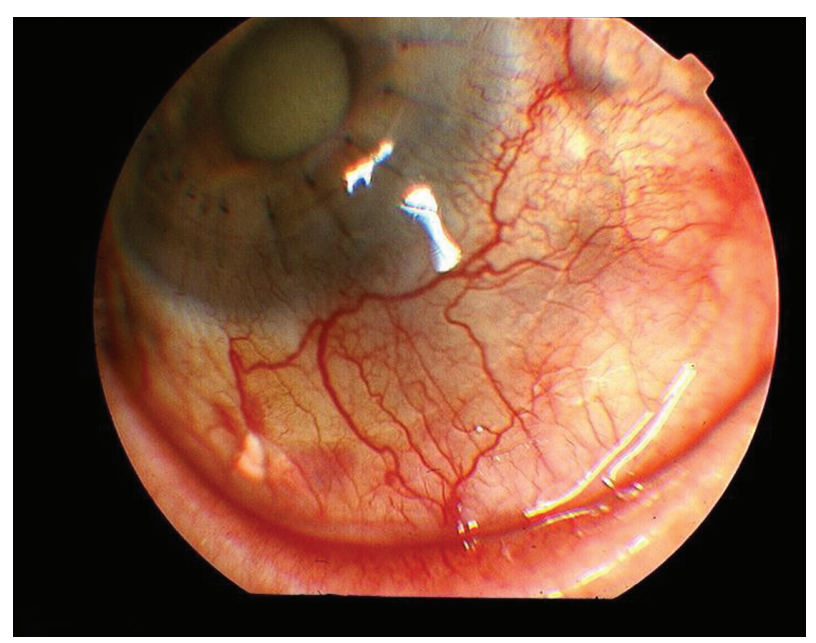

Figure I A) Affected eye at presentation with mild corneal edema and fine keratic precipitates. B) Scleritis with scleral thinning and subtenon's triamcinolone. moderate injection, and there was a white plaque consistent with triancinolone present beneath Tenons capsule superiorly. Intraocular pressure was $12 \mathrm{~mm} \mathrm{Hg}$. The anterior chamber appeared quiet, and the iris was dilated and unreactive. A mature cataract was present. The retina of the right eye could not be visualized, but ultrasound B scan showed a clear vitreous cavity and intact retina. Confocal microscopy (Confoscan 3 - Nidek) of the corneal graft showed cystic structures consistent with Acanthamoeba throughout the depth of the cornea (Figure 2). The left eye examination was normal.

Famcyclovir was discontinued, and topical propamidine, clotrimazole $1 \%$ and chlorhexidine $0.02 \%$ were added every hour for the first week and then decreased to every 2 hours. Prednisolone actetate 1\% was reduced to four times per day, and dorzolamide-timolol was reduced to twice per day. The moxifloxacin was continued.

One month after presentation the eye had shown no improvement. The patient was admitted to the hospital under the infectious disease service for a course of intravenous pentamidine. She was given intravenous pentamidine $200 \mathrm{mg}$ every 24 hours for 20 consecutive days. The treatment was associated with nausea, but no episodes of hypotension or hypoglycemia occurred. Her topical antiamebial therapy was continued for 20 days. Eleven days into this course of treatment a combined penetrating keratoplasty, cataract removal with lens implant was performed. Pathologic examination of the cornea demonstrated multiple stromal acanthamoebal cysts (Figure 3). Retinal examination following surgery demonstrated diffuse chorioretinal scarring but no evidence of active inflammation. Orbital and brain

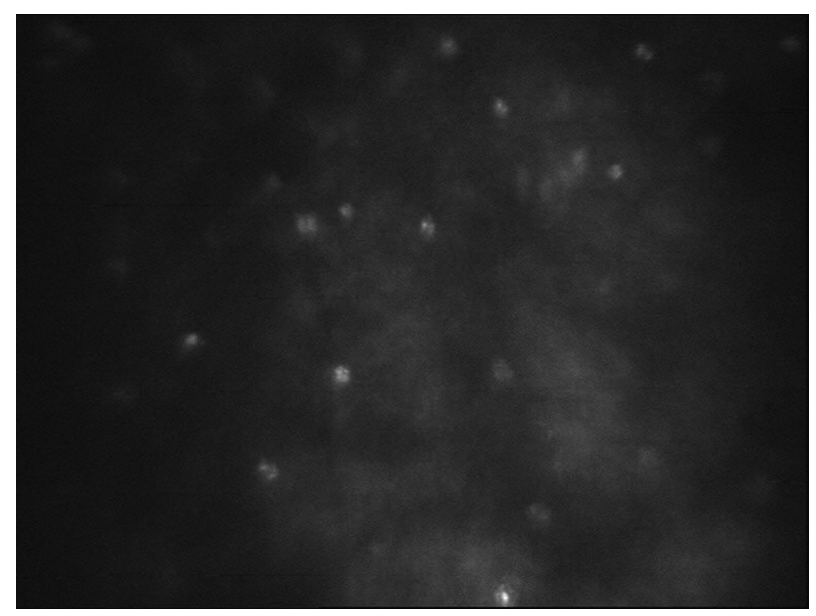

Figure 2 Confocal microscopy demonstrating cystic structures in the corneal stroma consistent with Acanthamoeba. 


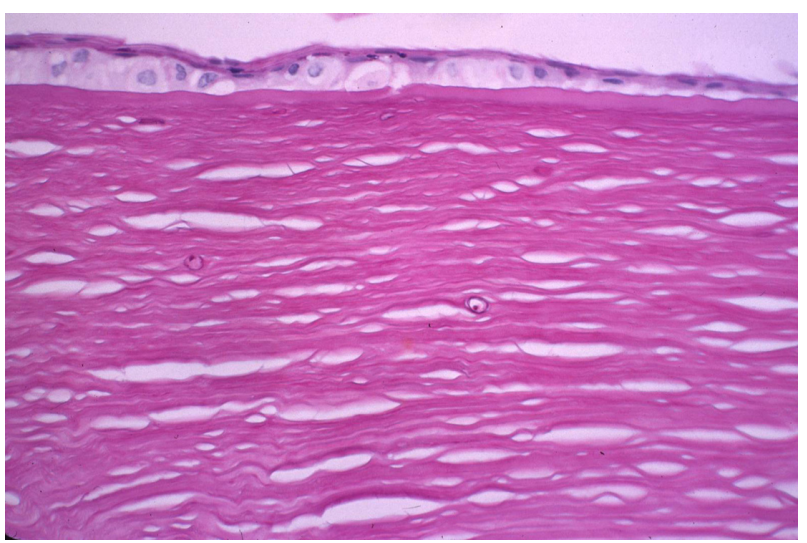

Figure 3 Stromal acanthamoebal cyst. PAS $\times 400$.

computed tomography (CT) scan and magnetic resonance imaging (MRI) were performed during the hospitalization and did not demonstrate any orbital or intracranial extension. She did have evidence of bilateral paranasal sinus disease. The patient was discharged in good condition. One month following her eye surgery her cornea was found to be clear with a quiet anterior chamber and posterior chamber lens implant. Scleral inflammation had improved significantly. Her pain had also improved. Vision was count fingers at 1 foot and was limited by the chorioretinal scarring. Her topical medications were moxifloxacin, Neosporin ${ }^{\circledR}$, PHMB, clotrimazole $1 \%$, chlorhexidine $0.02 \%$, and prednisolone actetate $1 \%$, all four times per day. She was also using atropine $1 \%$ and dorzolamide-timolol, each twice per day. She was using fluconazole orally.

The eye remained stable, and the patient continued her medications for 6 months when she presented with a 1 week

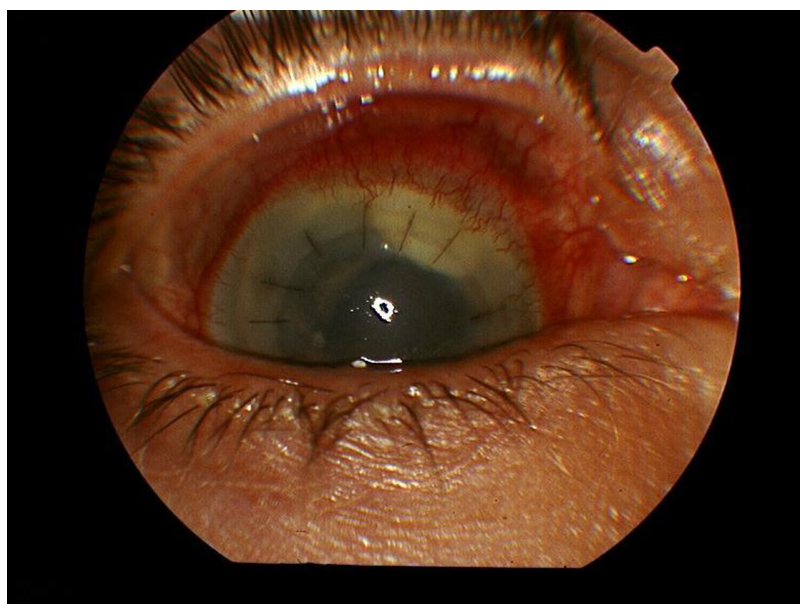

Figure 4 Loculated mass in superior anterior chamber with sclertitis. history of pain. Examination noted a $2 \mathrm{~mm}$ cream-colored loculated mass in the superior anterior chamber (Figure 4). The mass was removed in the operating room and sent for bacterial, fungal, and acanthamoebal cultures. Calcaflor white stain was negative for organisms. Cultures grew one colony of coagulase negative staphylococcus, which was felt to be a contaminant. Vancomycin $1.0 \mathrm{mg}$ was given intravitreally 2 days following surgery. The intraocular inflammation progressed over the next 3 weeks and a trans pars plana vitrectomy was performed with intravitreal injection of vancomycin $1.0 \mathrm{mg}$ and ceftazidine $2.25 \mathrm{mg}$. At the time of this surgery the patient was again admitted and given a 4-day course of intravenous pentamidine $200 \mathrm{mg}$ per day. Bacterial, fungal, and acanthamoebal cultures from the vitreous washings were all negative.

The postoperative medications were PHMB, clotrimazole, chlorhexidine, Neosporin, propamidine, and prednisolone actetate, all every hour for the first week and then tapered to 4 times per day. She was also on atropine $1 \%$ twice per day and oral ketaconazole. The eye remained inflamed and painful with vision of light perception but no accurate projection. Confocal microscopy demonstrated structures within the corneal stroma consistent with Acanthamoeba (Figure 5). Ultrasound demonstrated a funnel retinal detachment. The patient refused any additional treatment other than the topical medications. The eye was enucleated 3 months later due to severe pain. The patient has done well since enucleation with no evidence of recurrent disease. The pathology of the enucleated globe demonstrated acanthamoebal cysts within the cornea (Figure 6) and evidence of acute and chronic inflammation throughout the globe but no evidence of active organisms (Figure 7).

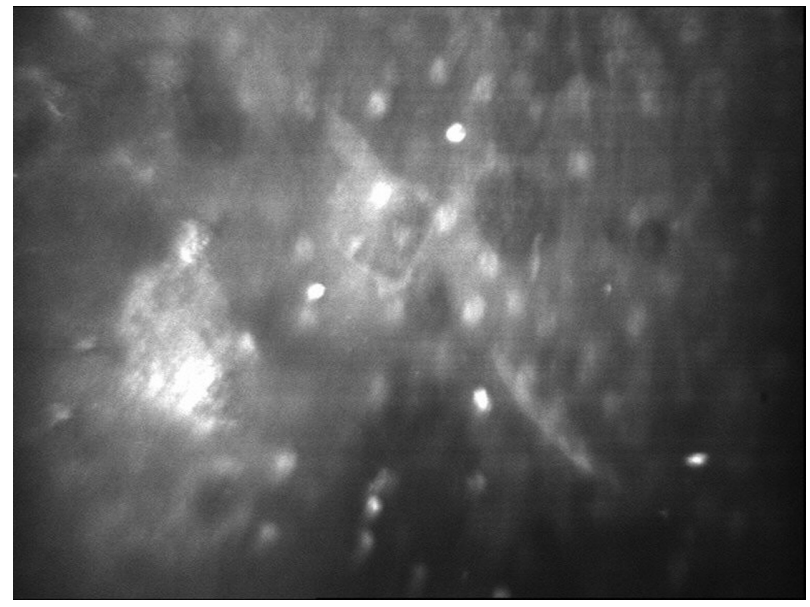

Figure 5 Confocal microscopy. 


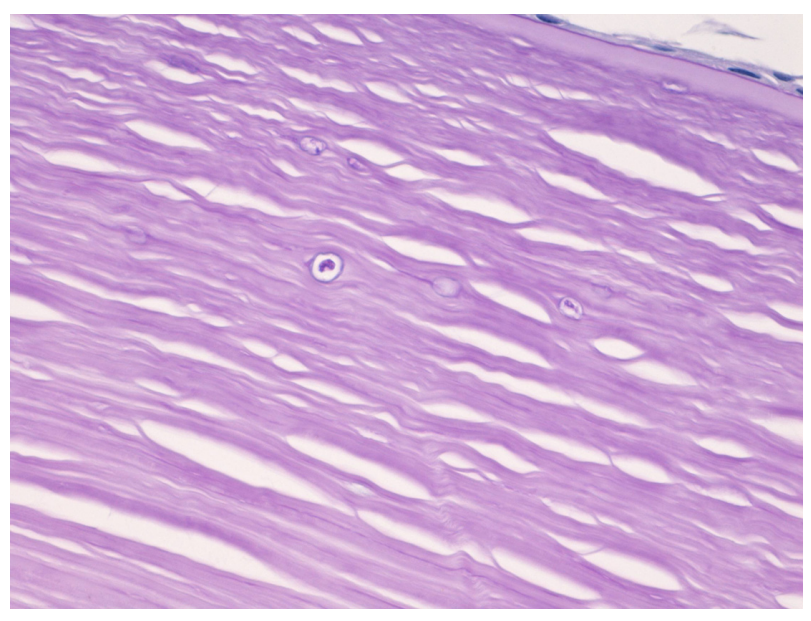

Figure 6 Acanthamoeba cysts within corneal stroma.

\section{Discussion}

The treatment of advanced Acanthamoeba sclerokeratitis is a challenge. ${ }^{1-3}$ It is diagnostically difficult to distinguish between secondary inflammatory reaction and actual acanthamoebal infection of the sclera. ${ }^{3}$ Topical treatment of the cornea may not achieve therapeutic levels in the sclera. ${ }^{12}$ Systemic treatment with ketaconazole and fluconazole has been used in the treatment of Acanthamoeba keratitis and sclerokeratitis. ${ }^{12}$ Pentamidine has been shown to have effectiveness against Acanthamoeba and has synergism with the biguanide compounds. ${ }^{4-10}$

The presence of chorioretinal inflammation in this eye does not necessarily indicate presence of Acanthamoeba in the posterior segment. Chorioretinal inflammation has been seen with the presence of Acanthamoeba ${ }^{13}$ and also as a sterile inflammation. ${ }^{14}$

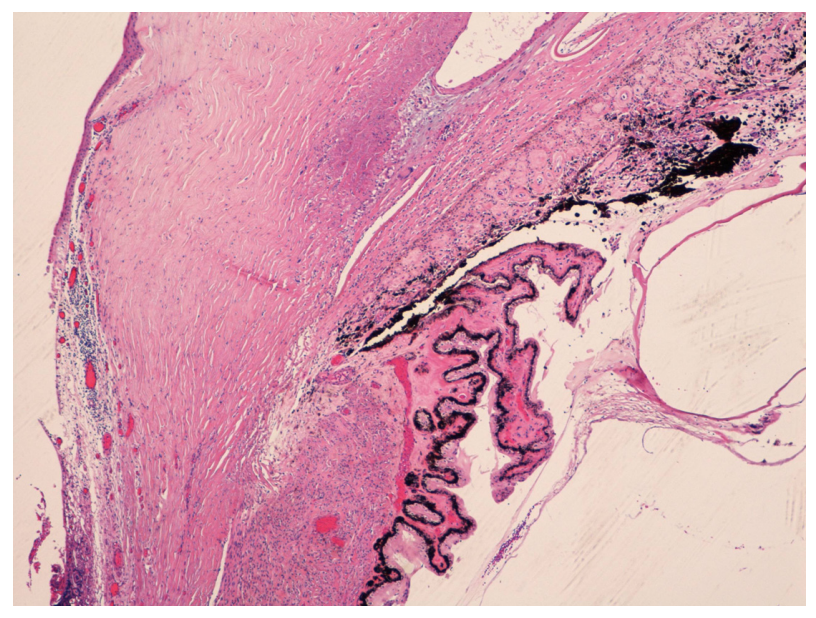

Figure 7 Inflammation in sclera, ciliary body, and choroid.
The sudden development of intense ocular inflammation in this patient after apparent successful treatment of the infection led to the concern that active infection had recurred. The failure of a prolonged therapeutic response to intravenous pentamidine could indicate that the treatment was of insufficient duration, that therapeutic levels were not attained and/or maintained, or that the Acanthamoeba was resistant to pentamidine.

If the scleritis was an immune-mediated response, ${ }^{3}$ then aggressive systemic immunosuppression may have changed the course of this case. This was not used in this case because of the concern that the Acanthamoeba was active.

It is clear that the use of systemic pentamidine in this case did not effectively alter the progression of the disease and eventual loss of the eye. Perhaps earlier intervention or combined systemic antiamebial therapy and immunosuppression would achieve a better outcome. Other systemic medications for the treatment of Acanthamoeba sclerokeratitis must be sought. Miltefosine and voriconazole have shown strong inhibitory effects on Acanthamoeba trophozoites in vitro and might be candidates for in vivo testing. ${ }^{15}$

\section{Disclosure}

The authors report no conflicts of interest in this work.

\section{References}

1. Dougherty PJ, Binder PS, Mondino BJ, Glasgow BJ. Acanthamoeba sclerokeratitis. Am J Ophthalmology. 1994;117(4):475-479.

2. Pineda R, Kocaturk T, Bhui RD. Visual outcome and rehabilitation in a case of bilateral Acanthamoeba sclerokeratitis. Cornea. 2007;26(9): 1150-1152.

3. Lee GA, Gray TB, Dart JK, et al. Acanthamoeba sclerokeratitis; treatment with systemic immunosuppression. Ophthalmology. 2002; 109(6):1178-1182.

4. Alizadeh H, Silvany RE, Meyer DR, et al. In vitro amoebicidal activity of propamidine and pentamidine isethionate against Acanthamoeba species and toxicity to corneal tissues. Cornea. 1997;16(1): 94-100.

5. Hay J, Kirkness CM, Seal DV, Wright P. Drug resistance and Acanthamoeba keratitis: the quest for alternative chemotherapy. Eye. 1994;8:555-563.

6. Oliva S, Jantz M, Tiernan R, et al. Successful treatment of widely disseminated acanthamoebiasis. South Med J. 1999;92(1):55-57.

7. Lim L, Coster DJ, Badennoch PR. Antimicrobial susceptibility of 19 Australian corneal isolates of Acanthamoeba. Clin Experiment Ophthalmol. 2000;28(2):119-124.

8. Lloyd D, Turner NA, Khunkitti W, et al. Encystation in Acanthamoeba castellanii: development of biocide resistance. J Eukaryot Microbiol. 2001;48(1):11-16.

9. Duma RJ, Finley R. In vitro susceptibility of pathogenic Naegleria and Acanthamoeba to a variety of therapeutic agents. Antimicrob Agents Chemother. 1976;10(2):370-376.

10. Schuster FL, Visvesvara GS. Opportunistic amoeba: challenges in prophylaxis and treatment. Drug Resist Update. 2004;7(1): $41-51$. 
11. Perez-Santonja JJ, Kilvington S, Hughes R, et al. Persistently culture positive Acanthamoeba keratitis: in vivo resistance and in vitro sensitivity. Ophthalmology. 2003;110(8):1593-1600.

12. Lindquist TD. Treatment of Acanthamoeba keratitis. Cornea. 1998; 17(1):11-16

13. Moshari A, McLean IW, Dodds MT, et al. Chorioretinitis after keratitis caused by Acanthamoeba: case report and review of the literature. Ophthalmology. 2001;108(12):2232-2236.
14. Awwad ST, Heilman M, Hogan RN, et al. Severe reactive ischemic posterior segment inflammation in Acanthamoeba keratitis: a new potential blinding syndrome. Ophthalmology. 2007;114(2):313-320.

15. Schuster FL, Guglielmo BJ, Visvesvara GS. In-Vitro activity of miltefosine and vorconazole on clinical isolates of free-living amebas: Balamuthia mandrillaris, Acanthamoeba spp., and Naegleria fowleri. J Eukaryot Nicrobiol. 2006;53(2):121-126.

\section{Publish your work in this journal}

Clinical Ophthalmology is an international, peer-reviewed journal covering all subspecialties within ophthalmology. Key topics include: Optometry; Visual science; Pharmacology and drug therapy in eye diseases; Basic Sciences; Primary and Secondary eye care; Patien Safety and Quality of Care Improvements. This journal is indexed on

Submit your manuscript here: http://www.dovepress.com/clinical-ophthalmology-journal

\section{Dovepress}

PubMed Central and CAS, and is the official journal of The Society of Clinical Ophthalmology (SCO). The manuscript management system is completely online and includes a very quick and fair peer-review system, which is all easy to use. Visit http://www.dovepress.com/ testimonials.php to read real quotes from published authors. 